\title{
Two for One: Integrating the Sustainable Development Agenda with International Climate Policy
}

2015 was a watershed for international sustainability governance. With the Paris climate agreement and Agenda 2030, the international community adopted new targets and processes which are to guide policy for decades to come. Both emphasise the need for integration. In practice, however, climate change and sustainable development have so far been siloed issues.
Wolfgang Obergassel, Florian Mersmann, Hanna Wang-Helmreich

Two for One: Integrating the Sustainable Development Agenda with International Climate Policy | CAIA 26/3 (2017): 249-253 Keywords: Agenda 2030, climate policy, Paris Agreement, SDGs, sustainable development

$\mathrm{D}$ evelopment issues have so far been central and marginal to international climate policy: they have been central in the sense that greenhouse gas (GHG) emission reductions and economic development have often been seen as antagonistic. Over the years, policymakers have repeatedly voiced concerns that ambitious climate policy would limit development, cut jobs, damage industry and reduce living standards (Moomaw and Papa 2012). At the same time, the climate-development nexus has hardly been explored. In climate policy, the risks of "carbon leakage" - that ambitious climate policy might induce shifts of industrial production to other countries - have been discussed extensively, but otherwise the debate has traditionally focused on counting GHG emissions, discounting wider socio-economic impacts of climate action as cobenefits and co-costs (Rosemberg 2010, Ürge-Vorsatz et al. 2014, Kumar et al. 2016). In development planning, climate change is often not taken into account by sectoral policymakers, as seen in ongoing planning on coal-based electricity generation or car-based transport infrastructure. The reason often lies in the siloed sectoral thinking of different ministries and a resulting lack of policy coherence (Nilsson et al. 2016).

The situation is supposed to improve with the implementation of two landmarks adopted in 2015: the Paris Agreement (PA) and Agenda 2030. Both stress the need for integration. In its preamble, the $P A$ emphasises "the intrinsic relationship that climate change actions, responses and impacts have with equitable access to sustainable development and eradication of poverty." Also, under the agreement's Article 2, its objectives are to be achieved "in the context of sustainable development and efforts to eradicate poverty". Agenda 2030 includes climate action as one of the Sustainable Development Goals (SDGs) to be achieved by 2030, and stresses the interlinkages between and integrated nature of all SDGs. This article argues that better integration of the two agendas will be necessary for effective climate protection and a transition to sustainable development.

\section{Mitigation Activities and SDGs: A Complex Relationship}

Actions to fulfil one SDG may impact others in some way - often positively, but also negatively (Ürge-Vorsatz et al. 2014, Nilsson et al. 2016). In this section, we unpack impacts of climate mitigation measures that go beyond mere GHG abatement. We discuss the main effects of climate mitigation measures on environmental, social and economic development in two sectors: electricity supply and urban transport.

\section{Electricity Supply}

Providing sustainable energy for all, as enshrined in SDG \#7, in the context of combating climate change (SDG \#13) will require energy generation systems that are virtually free of GHG emissions. Also, rural electrification is often easier to acquire through

Contact: Wolfgang Obergassel, M. A. | Tel.: +49202 2492149 |

E-Mail: wolfgang.obergassel@wupperinst.org

Dipl.-Verw. Florian Mersmann | E-Mail: florian.mersmann@wupperinst.org Dipl.-Reg.-Wiss. Lat. Hanna Wang-Helmreich | E-Mail: hanna.wang-helmreich@wupperinst.org all: Wuppertal Institute for Climate, Environment and Energy | Wuppertal | Germany

(c) 2017 W. Obergassel et al.; licensee oekom verlag. This is an article distributed under the terms of the Creative Commons Attribution License (http://creativecommons.org/licenses/by/3.0), which permits unrestricted use, distribution, and reproduction in any medium, provided the original work is properly cited. 
decentralised renewable energy than through centralised thermal generation systems.

Research points to multiple positive effects of renewable energy use (IPCC 2012, United Nations Climate Change Secretariat 2015, Helgenberger 2015). Most renewable energy sources are beneficial to human health (SDG \#3). ${ }^{1}$ Moreover, rural use of renewable energy systems can greatly benefit human development. For example, lighting systems create better learning opportunities ( $S D G$ \#4), electricity is the basis for the provision of modern communication systems ( $S D G \# 9$ ) that in turn have great economic and social impacts for farmers and local markets (SDG \#1, 8), electrical cooking appliances can free up time for women and children that was previously spent gathering fuel wood and provide healthier living conditions (SDGs \#1, 3, 5, 10).

Implementation of renewable energy projects and programmes can, however, have detrimental effects on fulfilment of the SDGs. Time and again, civil society organisations and researchers have pointed to violations of the human rights of local populations caused by energy projects, impacting at least $S D G s \# 1,2,3,5$, and 10 (Obergassel et al. 2017). Also, electricity generation through biomass can come with significant trade-offs, such as displacing agriculture for staple foods like maize or corn in favour of energy crops for biofuels, leading to dangerous shortages of basic food supplies for the poor (SDGs \#1, 2, 12) (IPCC 2012).

\section{Urban Transport}

The transport sector has to implement mitigation strategies as well and it cuts across no less than twelve targets of nine SDGs directly or indirectly (targets of $S D G s \# 3,7,9,11,12$ directly, targets of SDGs \#2, 3, 6, 11, 12, 13 indirectly) (SLoCaT 2015). Most transport emissions stem from motorised road transport. Reducing the need for using roads altogether, for example, through optimised infrastructure and planning processes, encouraging a shift towards less-polluting travel modes (e. g., rail freight, public transport, bicycles, walking) and improvements in fuel and vehicle efficiency (c. f. Boehler-Baedeker et al. 2011, GIZ 2011, 2012), has many benefits that go beyond mere GHG abatement. For example, less vehicular travel means less local air pollution, and thus better public health (SDGs \#3, 11). In addition, active non-motorized forms of transport have positive health effects as well (see figure 1).

Many activities that foster sustainable transport are economically positive and have the potential to save trillions of dollars in the longer term (United Nations Climate Change Secretariat 2015). But there are also negative effects, for example, fuel switching can come at significant cost to sustainable development, as biofuels can rival agricultural areas for food production, and lead to largescale monocultures that can degrade soils (SDGs \#1,2,12). Irrigation systems needed for growing fuel plants at scale restrict access to drinking water and contaminate ground water with various toxic chemicals (SDG \#6). Biofuel production, for transport and for energy generation, is thus an activity that calls for in-depth weighing of its benefits and trade-offs. It is a pivotal part of the food-water-energy nexus so critical in the climate change domain, not only for mitigation, but also for adaptation (Liu 2016).

\section{Anchoring the SDGs within the Paris Agreement}

In the following, we outline options to better integrate sustainable development concerns into international climate policy. These include starting from a development perspective to envision contributions under the climate agreement, integrated longterm development planning and developing sustainable development criteria for climate protection projects.

\section{Development First instead of You First}

From the beginning, climate policy has suffered from a lack of ambition. Arguably, its framing has been a contributing factor: The United Nations Framework Convention on Climate Change (UNFCCC) has mostly focused on GHG emission targets. Emission targets for industrialised countries are at the core of the KYoto Protocol, and the PA's Article 4.4 encourages developing countries to move towards economy-wide emission targets over time. This approach is designed to reduce the possibility to emit GHGs, putting a price on emissions in order to encourage investments for low-GHG technologies and practices.

However, in most countries economic development has so far relied on use of fossil fuels, and has thus inextricably been connected to GHG emissions. A focus on GHG reductions may thus be sensible policy, but it is not necessarily sensible politics as it inevitably causes distributional conflicts. These are reflected in policymakers' frequent expressions of concern about overly restricting national access to "carbon space" or "development space", which is seen as a prerequisite for economic well-being and development. Thus, political incentives point strongly towards adopting weak rather than strong emission targets. The dominant narrative in the UNFCCC has consequently been to see climate protection as a burden to be shared - with each country trying to shift as much of this perceived burden to other countries. When discussing the UNFCCC's core principle of common but differentiated responsibilities, countries have mainly focused on the responsibilities of the others, with developing countries pointing to the historical responsibility of industrialised countries and industrialised countries pointing to the rapidly rising emissions in developing countries. This burden-sharing narrative might be overcome by considering other types of contributions that provide better links with national development aspirations and thus more potential to mobilise political support (Winkler et al. 2002, Moomaw and Papa 2012, Hermwille et al. 2017).

The Nationally Determined Contributions (NDCs) under the PA indicate some movement in this direction. While most of the NDCs submitted contain emission targets only, 20 combine emission targets with other targets and 35 contain purely non-GHG targets and/or actions (WRI 2017). China and India show that combining multiple contributions may indeed have the potential for enhancing ambition. Both countries have submitted emission

\footnotetext{
1 Respiratory health especially improves, as most renewables - except biomass burning - do not emit combustion gases.
} 
intensity targets and targets for the share of non-fossil energy sources. According to the Climate Action Tracker (CAT), these nonfossil energy targets imply significantly greater emission reductions than the emission targets. ${ }^{2}$

Moving forward, the SDGs and their sub-targets can help structuring NDCs that address both emission reductions and wider objectives, thus potentially mobilising stronger political support. For example, the sub-targets of SDG \#7 on affordable and clean energy - by 2030 increase substantially the share of renewable energy in the energy mix and to double the rate of improvement in energy efficiency - could be adopted as part of NDCs.

\section{A Two-Way Ambition Ratchet: Enhancing Commitments through Sustainable Development}

If elements of the SDGs were integrated into NDCs in this way, they would repeatedly be discussed internationally as part of the "ambition cycle" established by the PA. Parties to the PA have to communicate new or updated NDCs and assess collective progress on implementation of the agreement under a "global stocktake" every five years. The outcome of the stocktake is to inform Parties in updating and enhancing their contributions.

This could mean a two-way strengthening of ambition: in the first step, complementing GHG targets with elements from other SDGs with strong GHG reduction potential, such as sustainable energy targets, could help make the NDCs more ambitious than they might otherwise be. In the second step, the PA's provisions for frequent review and strengthening of NDCs could facilitate implementation and strengthening of those SDG elements.

\section{Long-Term Development Planning through an Integrated Climate-Sustainable Development Agenda}

Climate change mitigation and sustainable development require fundamental long-term transformation of economies and societies. Consequently, both agendas call on countries to establish integrated long-term planning. Ideally, countries would develop one integrated strategy instead of separate strategies for the two agendas.

Implementing such an integrated approach would require establishing intensive cooperation among ministries which has so far often been lacking. In many countries, climate and sectoral development agendas have traditionally been dealt with by different ministries or other public institutions that do not swap ideas by all means and often compete for political attention and funding (Horn-Phathanothai and Waskow 2016). To overcome such institutional barriers, integration will need to be mandated by the highest possible political level. In some countries, such as Argentina and El Salvador, a dedicated sustainable development and climate policy cabinet has been formed already (Hirsch 2017).

\section{Sustainable Development Criteria for Better Climate Protection Projects}

The PA contains various approaches for cooperation and provision of support from richer to poorer countries. Article 9 requires developed countries to provide financial resources to assist developing countries in adaptation and mitigation, reiterating an obligation already contained in the UNFCCC. Also, Article 6 enables countries to cooperate in achieving their contributions, with the objectives "to allow for higher ambition in their mitigation and adaptation actions and to promote sustainable development and environmental integrity." In contrast to cooperation under Article 6, the provision of public climate finance has no explicit mandate to promote sustainable development. Nonetheless, the $P A$ 's objectives are to be achieved "in the context of sustainable development and efforts to eradicate poverty." Public climate finance should therefore also strive for a synergistic approach, integrating emission reductions and achievement of other SDGs.

2 According to CAT calculations, the emission intensity target could lead to national emissions of 14.7 to 16.5 gigatons $\mathrm{CO}_{2}$-eq. in 2030 in China and 5.9 to 6.0 gigatons $\mathrm{CO}_{2}$-eq. in India. The non-fossil energy target would lead to only 13.2 to 13.6 and 5.3 to 5.5 gigatons $\mathrm{CO}_{2}$-eq. respectively (Climate Action Tracker 2016a, 2016b). 
The SDGs may be seen as a universally agreed metric for measuring, reporting and verifying sustainable development that could be used to assess internationally funded climate actions (Dransfeld et al. 2017, Olsen et al. 2017). If this idea of a universal metric were to be applied, three questions would have to be asked where projects are concerned:

- To what extent does the project contribute positively to the achievement of SDGs?

- Are there risks that the project may have negative impacts on $S D G s$ ?

- What preventive measures are envisaged with the project to avoid, minimise or compensate for such negative impacts?

\section{Conclusions}

Climate actions can have multiple impacts that go beyond mere emission abatement. Many are extremely positive, such as improved health, educational effects, gender equality and more. But strong scrutiny is needed to ensure that climate protection does not impede fulfilling other parts of the SDG agenda, such as access to food and water, and is at least in line with human rights around the world. At the same time, the other SDGs must take climate protection into account. Otherwise, implementation of goals such as enhancing access to mobility may easily lead to higher GHG emissions.
The international climate regime, therefore, must better integrate sustainable development concerns. So far, international climate policy has strongly focused on emission targets, which has arguably contributed to climate protection and development being seen as antagonistic.

To be effective, climate protection and sustainable development policies must overcome this antagonism.

First, it would be helpful to supplement emission targets with other types of contributions that are anchored in national development priorities and have emission reductions as a "co-benefit", such as renewable energy targets. The examples of China and India show that contributions that are not GHG-based may indeed be more ambitious than GHG targets. The SDGs and their subtargets could provide inspiration for how to structure climate contributions that address both emission reductions and wider development objectives.

Second, if elements of the SDGs were integrated into NDCs in this way, they would repeatedly be discussed internationally as part of the "ambition cycle" established by the PA. This could facilitate implementation and further strengthening of those SDG elements.

Third, both sustainable development and climate policy should be fully embedded in national development planning in all sectors.

\section{GAIA Masters Student Paper Award}

\section{Have your work awarded and published in a renowned scientific journal!}

The international journal GAIA - Ecological Perspectives for Science and Society invites liasters students to participate in the 2018 GAIA liasters Student Paper Award.

Miasters students are encouraged to publish

their results from research-based courses/liasters theses in the field of transdisciplinary environmental and sustainability science.

Deadine for submission: Hovember 6,2017. Anticipated publication date: June 2018.

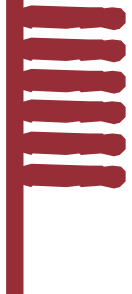

One article will be selected by a jury and published in GAIA. The winner will be granted a prize money of EUR 1,500 endowed by the Selbach Umwelt Stiftung, as well as a free one-year subscription to GAIA, including free online access. 
To overcome institutional inertia, integration will need to be mandated and institutionalised at the highest possible political level.

Finally, the SDGs can provide a solid basis on which to assess sustainable development impacts of internationally funded climate projects that exceed a pure GHG abatement metric. If negative SDG impacts outweigh GHG abatement benefits, integration of $S D G$ impacts may well change the priority order of projects in the medium term.

Further research could develop technical underpinnings for the approaches explored in this article. For example, research could analyse the applicability of the internationally agreed SDG indicators for assessing sustainable development impacts of climate projects. A further question to be looked at is whether there is room to create synergies between the reporting procedures under the PA and Agenda 2030.

\section{References}

Boehler-Baedeker, S., H. Hüging, R. Gruber. 2011. Navigating towards efficient urban transport: A compilation of actor oriented policies and measures for developing and emerging countries. Paper presented at the conference Energy Efficiency First: The Foundation of a Low-Carbon Society. Belambra Presqu'île de Giens, France, June 6-11.

Climate Action Tracker. 2016a. China. Climate Action Tracker. http://climate actiontracker.org/countries/china.html (accessed November 2, 2016).

Climate Action Tracker. 2016b. India. Climate Action Tracker. http://climate actiontracker.org/countries/india.html (accessed November 2, 2016).

Dransfeld, B. et al. 2017. SD-benefits in future market mechanisms under the UNFCCC. Climate Change 04/2017. Dessau: Umweltbundesamt. www.umweltbundesamt.de/en/publikationen/sd-benefits-in-futuremarket-mechanisms-under-the (accessed September 6, 2017).

GIZ (Deutsche Gesellschaft für Internationale Zusammenarbeit). 2011. Sustainable urban transport: Avoid-shift-improve (A-S-I). Factsheet. Eschborn: GIZ. www.sutp.org/files/contents/documents/resources/E_Fact-Sheetsand-Policy-Briefs/SUTP_GIZ_FS_Avoid-Shift-Improve_EN.pdf (accessed September 6, 2017).

GIZ. 2012. Navigating transport NAMAs. Practical handbook for the design and implementation of nationally appropriate mitigation actions (NAMAs) in the transport sector. Eschborn: GIZ. www.transferproject.org/index.php/hb (accessed August 29, 2017).

Helgenberger, S. 2015. Mobilizing the co-benefits of renewable energies lessons to be learned from Germany and China. Potsdam: Institute for Advanced Sustainability Studies (IASS). www.iass-potsdam.de/sites/default/files/files/ iae-iass_cobenefits_helgenberger_160924.pdf (accessed August 29, 2017).

Hermwille, L., W. Obergassel, H. E. Ott, C. Beuermann. 2017. UNFCCC before and after Paris - What's necessary for an effective climate regime? Climate Policy 17/2: 150-170.

Hirsch, T. 2017. Ambition, participation and effectiveness. Utilising the NDC partnership as a catalyst for NDC implementation in developing countries. Berlin: Bread for the World.

Horn-Phathanothai, L., D. Waskow. 2016. Commentary: Making the links real. www.wri.org/news/commentary-making-links-real (accessed September 6, 2017).

IPCC (Intergovernmental Panel on Climate Change). 2012. Renewable energy sources and climate change mitigation. Special report. Cambridge, UK: Cambridge University Press.

Kumar, S., A. Americo, C. Billingham. 2016. The new social contract: A just transition. Brussels: Foundation for European Progressive Studies \& Change Partnership. www.changepartnership.org/campaigns/ campaignsjusttransition (accessed September 6, 2017).
Liu, Q. 2016. Interlinking climate change with water-energy-food nexus and related ecosystem processes in California case studies. Ecological Processes 5/1. doi:10.1186/s13717-016-0058-0.

Moomaw, W., M. Papa. 2012. Creating a mutual gains climate regime through universal clean energy services. Climate Policy 12/4: 505-520.

Nilsson, M., D. Griggs, M. Visbeck. 2016. Policy: Map the interactions between sustainable development goals. Nature 534/7607: 320-322.

Obergassel, W., L. Peterson, F. Mersmann, J. Schade, J. A. Hofbauer, M. Mayrhofer. 2017. Human rights and the clean development mechanism: Lessons learned from three case studies. Journal of Human Rights and the Environment 8/1: 51-71.

Olsen, K. H., C. Arens, F. Mersmann. 2017. Learning from CDM SD Tool experience for Article 6.4 of the Paris Agreement. Climate Policy. doi:10.1080/14693062.2016.1277686.

Rosemberg, A. 2010. Building a just transition. The linkages between climate change and employment. International Journal of Labour Research 2/2: 125-162.

SLoCaT (Partnership on Sustainable Low Carbon Transport). 2015. Contribution of transport commitments to global goals on sustainable development. www.slocat.net/sites/default/files/u13/2015_transport_commitments_ report_2.pdf (accessed September 6, 2017).

United Nations Climate Change Secretariat. 2015. Climate action now: Summary for policymakers 2015. Bonn: United Nations Climate Change Secretariat. http://climateaction2020.unfccc.int/media/1173/ 21789-spm-unfccc-lowres.pdf (accessed September 6, 2017).

Ürge-Vorsatz, D., S. Tirado Herrero, N. K. Dubash, F. Lecocq. 2014. Measuring the co-benefits of climate change mitigation. Annual Review of Environment and Resources 39/1: 549-582.

Winkler, H., R. Spalding-Fecher, S. Mwakasonda, O. Dawidson. 2002. Sustainable development policies and measures: Starting from development to tackle climate change. In: Building on the Kyoto Protocol: Options for protecting the climate. Edited by K. A. Baumert, O. Blanchard, S. Llosa, J. F. Perkaus. Washington, D. C.: World Resources Institute. 61-88. http://pdf.wri.org/opc_full.pdf (accessed September 6, 2017).

WRI (World Resources Institute). 2017. CAIT Paris contributions map: Explore intended nationally determined contributions (INDCs). http://cait.wri.org/indc/\#/map (accessed September 4, 2017).

Submitted May 31, 2017; revised version accepted August 28, 2017.

Wolfgang Obergassel

Born 1976 in Cologne, Germany. M. A. in history of international relations, London School of Economics and Political Science, UK. Project co-ordinator at the Wuppertal Institute for Climate, Environment and Energy. Research interests: development of the international climate regime, transformational change, equity.

Florian Mersmann

Born 1980 in Kiel, Germany. Diploma of administrative sciences, University of Potsdam, Germany. Research fellow at the Wuppertal Institute for Climate, Environment and Energy. Research interests: international climate policy, transformational change, low-carbon development.

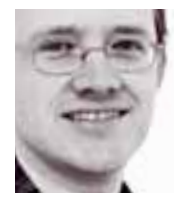

Hanna Wang-Helmreich

Born 1981 in Nuremberg, Germany. Diploma in regional sciences of Latin America, University of Cologne, Germany.

Research fellow at the Wuppertal Institute for Climate, Environment and Energy. Research interests: international climate policy, co-benefits and co-costs of climate protection measures, scenario based economic and potential analyses. 